\title{
Characterizing ENSO Coupled Variability and Its Impact on North American Seasonal Precipitation and Temperature*
}

\author{
MiCHELLE L. L'HeUREUX \\ National Oceanic and Atmospheric Administration/National Weather Service/National Centers for \\ Environmental Prediction, Climate Prediction Center, College Park, Maryland \\ MICHAEL K. TIPPETT \\ Department of Applied Physics and Applied Mathematics, Columbia University, New York, \\ New York, and Center of Excellence for Climate Change Research, Department of Meteorology, \\ King Abdulaziz University, Jeddah, Saudi Arabia \\ ANTHONY G. BARNSTON \\ International Research Institute for Climate and Society, The Earth Institute of Columbia \\ University, Palisades, New York
}

(Manuscript received 21 July 2014, in final form 11 February 2015)

\begin{abstract}
Two questions are addressed in this paper: whether ENSO can be adequately characterized by simple, seasonally invariant indices and whether the time series of a single component—SST or OLR—provides a sufficiently complete representation of ENSO for the purpose of quantifying U.S. climate impacts. Here, ENSO is defined as the leading mode of seasonally varying canonical correlation analysis (CCA) between anomalies of tropical Pacific SST and outgoing longwave radiation (OLR). The CCA reveals that the strongest regions of coupling are mostly invariant as a function of season and correspond to an OLR region located in the central Pacific Ocean (CP-OLR) and an SST region in the eastern Pacific that coincides with the Niño-3 region. In a linear context, the authors explore whether the use of a combined index of these SST and OLR regions explains additional variance of North American temperature and precipitation anomalies beyond that described by using a single index alone. Certain seasons and regions benefit from the use of a combined index. In particular, a combined index describes more variability in winter/spring precipitation and summer temperature.
\end{abstract}

\section{Background}

Prior to the major El Niño of 1997/98, Barnston et al. (1997) published a study whose goal was to provide a single time series, or index, that would capture the essence of the El Niño-Southern Oscillation (ENSO)

\footnotetext{
* Supplemental information related to this paper is available at the Journals Online website: http://dx.doi.org/10.1175/JCLI-D-1400508.s1.

Corresponding author address: Michelle L'Heureux, National Oceanographic and Atmospheric Administration/Climate Prediction Center, 5830 University Research Court, Rm. 3115, W/NP52, College Park, MD 20740.

E-mail: michelle.lheureux@noaa.gov
}

phenomenon. The resulting Niño-3.4 index is the departure from its long-term average of sea surface temperatures (SST) across the east-central equatorial Pacific, averaged within $5^{\circ} \mathrm{S}-5^{\circ} \mathrm{N}, 170^{\circ}-120^{\circ} \mathrm{W}$. This region straddled the previously defined Niño-3 $\left(150^{\circ}-\right.$ $\left.90^{\circ} \mathrm{W}\right)$ and Niño- $4\left(160^{\circ} \mathrm{E}-150^{\circ} \mathrm{W}\right)$ regions, which were identified in the 1980s. Barnston et al. (1997) identified the Niño-3.4 region on the basis of the relationship between SST and the Southern Oscillation index (SOI), and on the basis of climate variations influenced by ENSO, such as Atlantic hurricane activity.

Today, the Niño-3.4 SST index and the oceanic Niño index (ONI), the 3-month running average of Niño-3.4, have become the backbone of operational monitoring and prediction of ENSO (Trenberth 1997; Kousky and Higgins 2007; Barnston et al. 2012; Tippett et al. 2012). 
Despite the utility of the Niño-3.4 index, the increasing observational record makes it clear that no single index completely characterizes ENSO and its impacts. Other indices complement Niño-3.4, such as the SOI (Walker and Bliss 1932; Van Loon and Madden 1981; Ropelewski and Halpert 1986), the multivariate ENSO index (MEI; Wolter and Timlin 2011), and the bivariate ENSO (BEST) index (Smith and Sardeshmukh 2000), just to name a few. Additionally, "ENSO flavor" indices have been developed to distinguish between different types of ENSO events, keying in on factors such as strength, frequency, and the east-west extent of SST anomalies across the tropical Pacific (Larkin and Harrison 2005; Ashok et al. 2007; Kao and Yu 2009; Takahashi et al. 2011; Furtado et al. 2012; L'Heureux et al. 2013; Johnson 2013; Lopez and Kirtman 2013; Karnauskas 2013). All of these indices provide additional texture to the picture of ENSO as a multidimensional, coupled ocean-atmosphere mode of climate variability.

One of the goals of this paper is to revisit the approach of Barnston et al. (1997) in which ENSO was characterized on the basis of the relationship between sea level pressure and oceanic variables. While SST is a natural choice of variable with which to characterize the ocean component of ocean-atmosphere coupled variability, there are many choices of variable for the atmospheric component. In the tropics, the first-order thermodynamic balance is between heating and vertical motion (Charney 1963). Ultimately, these quantities are reflected in atmospheric convection, which can be identified using precipitation or outgoing longwave radiation (OLR; Stechmann and Ogrosky 2014). Satellites provide temporally and spatially complete estimates of OLR continuously since 1979, whereas rainfall estimates based on merged satellite- and gauge-based observations are especially uncertain over the ocean (Gruber et al. 2000; Yin et al. 2004). As such, ENSO-related convection has often been identified using OLR. The use of OLR is also attractive because atmospheric heating, in turn, drives the global atmospheric circulation, temperature, and precipitation anomalies.

The role of tropical Pacific OLR as a driver of ENSO impacts is highlighted in work by Chiodi and Harrison (2010, 2013), which argues for an OLR-based classification of ENSO. Their approach is nonlinear in the sense that they examine the OLR pattern associated with the warm ENSO (El Niño) state and do not assume that this pattern is the opposite of the OLR pattern for cold ENSO (La Niña) states. For El Niño, Chiodi and Harrison (2013) define an eastern Pacific OLR (EPOLR) region $\left(5^{\circ} \mathrm{S}-5^{\circ} \mathrm{N}, 160^{\circ}-110^{\circ} \mathrm{W}\right)$ and demonstrate that the four largest EP-OLR events in the period 19792008 correspond with substantial seasonal temperature and precipitation impacts across the United States.
These studies, among others (e.g., Yulaeva and Wallace 1994) show that anomalies in tropical Pacific OLR have a global-scale influence during ENSO, and therefore support the selection of OLR to represent the atmospheric component of coupled ocean-atmospheric variability associated with ENSO.

While other atmospheric and oceanic variables across the tropical Pacific could be offered as a substitute or addition to SST- and OLR-based indices, here we take a parsimonious approach with one variable representing the ocean and one based on the atmosphere. For monthly and seasonal averages, OLR and SST are strong candidates because they are clearly coupled, while other tropical variables, such as winds and atmospheric pressure, can be interpreted as mostly the consequence of the SST-OLR relationship (e.g., Lindzen and Nigam 1987). Recent work by Back and Bretherton $(2009 a, b)$ further demonstrates that lowlevel convergence, and the resulting vertical motion or diabatic heating, is primarily due to SST gradients. In their model, the location and magnitude of SST anomalies and gradients can largely predict where tropical vertical motion and rainfall occurs.

A final goal of this work is to use our selected indices for ENSO coupled variability to evaluate ENSO's influence on North American climate. The influence of ENSO has been established in numerous studies (e.g., Ropelewski and Halpert 1986), but here we examine the question of whether an SST or OLR index by itself provides a better description of impacts or whether the use of a combined index represents an improvement over each index alone. Our motivation is not to establish the superiority of our indices, vis-à-vis other ENSO indices, in explaining U.S. temperature and precipitation variability, but to simply demonstrate how our understanding of ENSO impacts can vary depending on whether a single constituent index is used or not.

We focus on linear techniques for capturing the relationship between tropical Pacific OLR and SST, and then for identifying connections with North American climate. Chiodi and Harrison (2010, 2013) feature an OLR index that represents the strongest El Niño events and signals over North America and is nonlinearly related to SST anomalies. There is merit in this perspective, but there are also certain advantages conferred by a linear approach, among them is less sensitivity to sampling and accommodation of all ENSO phases.

Our paper is organized as follows. After describing the data and primarily linear methods in section 2, the leading mode of Pacific coupled ocean-atmosphere variability is identified using a canonical correlation analysis (CCA) between tropical Pacific SST and OLR (section 3a). The goal of the CCA is to construct an objective 
definition of ENSO as the leading mode of coupled tropical Pacific variability. Extending the work of Barnston et al. (1997) and others, we examine seasonal dependencies over all 12 overlapping seasons, emphasizing the most robust, large-scale response in OLR and in a relatively modern SST dataset. Regionally averaged SST and OLR indices are identified based on their correlation to the leading CCA mode. In section $3 \mathrm{~b}$, we show the strength and degree of linear dependence between a fixed, regional SST index and different regional OLR indices. Finally, using a framework of linear hypothesis testing and field significance identifies the relative advantage of characterizing ENSO impacts on North American seasonal climate using either an SST or OLR index alone or using both indices (section 3c). We conclude with a summary and discussion in section 4 .

\section{Data and methods}

Monthly averaged OLR data are taken from the NOAA interpolated OLR product available on a global $2.5^{\circ}$ latitude $\times 2.5^{\circ}$ longitude grid (Liebmann and Smith 1996). Monthly averaged SST is taken from the optimal interpolation SST, version 2 (OISSTv2; Reynolds et al. 2002, 2007), regridded to a $2.5^{\circ} \times 2.5^{\circ}$ resolution using box averaging. Our analysis here covers the 32-yr period from January 1982 through November 2013. Seasonal anomalies are computed with respect to the period 1982-2012.

For precipitation over North America $\left(20^{\circ}-70^{\circ} \mathrm{N}, 170^{\circ}-\right.$ $60^{\circ} \mathrm{W}$ ), we use monthly averages of the CPC unified gaugebased precipitation product produced on a $0.5^{\circ}$ latitude $\times$ $0.5^{\circ}$ longitude grid (Chen et al. 2008). Monthly averages of near-surface temperature on the same grid are drawn from the station-based combined Global Historical Climatology Network and Climate Anomaly Monitoring System $(\mathrm{GHCN}+\mathrm{CAMS})$ dataset provided by CPC (Fan and Van den Dool 2008). For both datasets, station coverage over much of Canada and Alaska is sparse and limited, and the results tend to show little signal in these areas.

CCA is used to determine the patterns of the coupled response between OLR and SST. The dimensions of the SST and OLR fields are first reduced (Barnett and Preisendorfer 1987) through empirical orthogonal functions/principal component (PC) analysis. In this application of CCA, approximately $70 \%$ of the original variance is retained in each dataset so that from three to eight EOFs are used depending on season and variable. The CCA finds linear combinations of OLR and SST (canonical variates) that are maximally correlated. The spatial character of the canonical variates is expressed here in the form of homogeneous correlation maps, produced by correlating the canonical variates with the original input data.
Here, we define "linear" as a straight line, least squares best fit through the data. A linear regression model is constructed to judge the impact of the predictor indicesSST and OLR - on a predictand time series of temperature or precipitation anomalies at each North America grid point. In the two-predictor framework, both equal weights and unequal weights are tested, with unequal weights determined by solving the following equation:

$$
y=a x_{\mathrm{SST} / \mathrm{OLR}}+b x_{\mathrm{OLR} / \mathrm{SST}}+c,
$$

where $y$ is the predictand, $x$ is the SST or OLR index, and the weights $(a, b$, and $c)$ are the multiple linear regression coefficients.

Regression models that are "nested," that is, the predictors in one are a subset of the predictors in the other, can be compared using an $F$ test. Here we use this procedure to determine whether a single predictor model (e.g., an SST index) is significantly improved by the addition of a second predictor (e.g., some OLR index). The $F$ statistic used is

$$
F=\frac{\left(\frac{\mathrm{RSS}_{1}-\mathrm{RSS}_{2}}{p_{2}-p_{1}}\right)}{\left(\frac{\mathrm{RSS}_{2}}{n-p_{2}}\right)},
$$

where RSS represents the residual sum of squares of model 1 and model 2, $p$ is the number of parameters in each model (number of predictors + the intercept), and $n$ is the number of data points (number of years).

Field significance is determined as in Livezey and Chen (1983) with a Monte Carlo simulation. The null hypothesis distribution is simulated by generating 1000 Gaussian-distributed random time series and correlating them with North American temperature and precipitation. The percentage of cosine-weighted grid boxes with correlations that exceed the $95 \%$ significance level (via a Student's $t$ distribution) is recorded for each random time series, and the 95th percentile $(N)$ of these areal fractions is computed. Correlation maps with significant areas less than $N$ are deemed to be not field significant. This procedure does not take into account the strength and the spatial coherence of the observed correlations (DelSole and Yang 2011).

\section{Results}

\section{a. The leading mode of tropical Pacific coupled SST and $O L R$ variability}

A seasonally dependent CCA was calculated between fields of tropical Pacific SST and OLR anomalies. The 

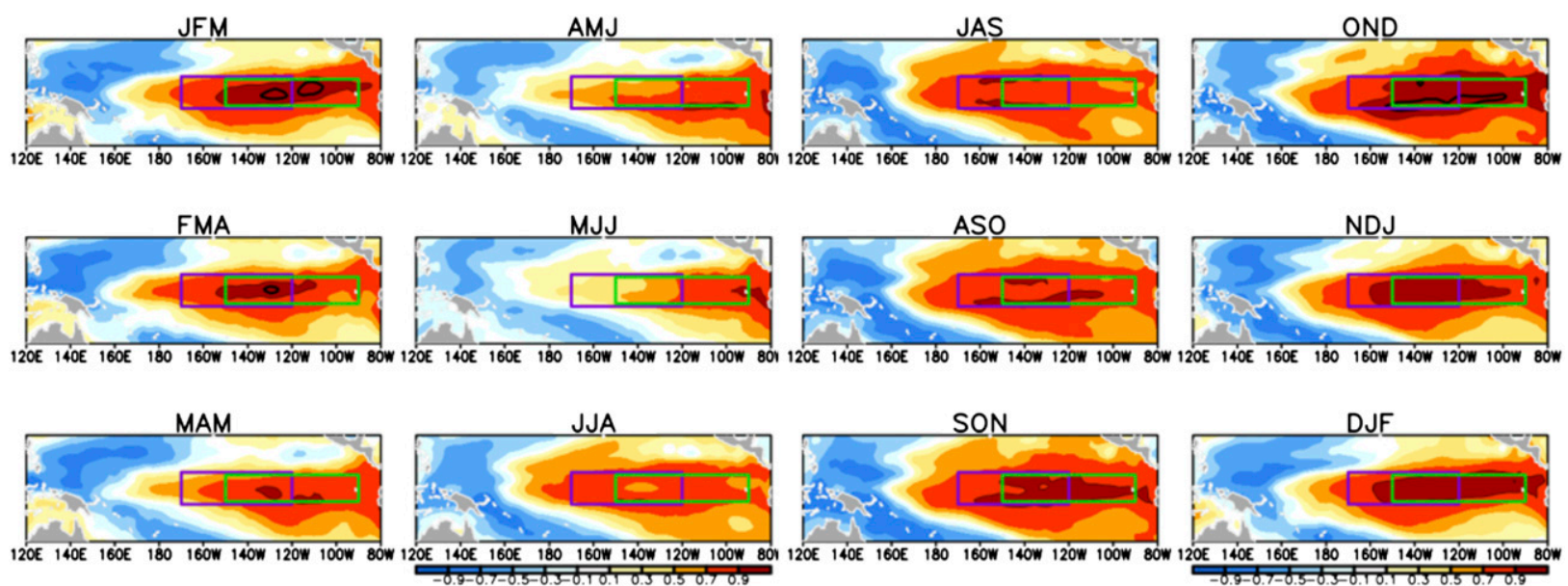

FIG. 1. Homogeneous correlation maps of sea surface temperature anomalies over the tropical Pacific $\left(20^{\circ} \mathrm{S}-20^{\circ} \mathrm{N}, 120^{\circ} \mathrm{E}-80^{\circ} \mathrm{W}\right)$ for 3-month overlapping seasons from 1982 to 2013. The thin (thick) black contour indicates a correlation coefficient of 0.9 (0.95). The green box indicates the Niño-3 region $\left(5^{\circ} \mathrm{S}-5^{\circ} \mathrm{N}, 150^{\circ}-90^{\circ} \mathrm{W}\right)$ and the purple box denotes the Niño-3.4 region $\left(5^{\circ} \mathrm{S}-5^{\circ} \mathrm{N}, 170^{\circ}-120^{\circ} \mathrm{W}\right.$; shown at a slight offset for visibility).

components of the leading CCA mode are shown in Figs. 1 and 2 in the form of correlation maps of SST and OLR, respectively. As expected, correlations in SST and OLR are largest and most widespread during the Northern Hemisphere winter, extending across most of the equatorial Pacific Ocean. During the Northern Hemisphere spring and early summer [April-June (AMJ) and May-July (MJJ)], the highest correlations become more confined to the far eastern Pacific. This behavior is likely related to the mean state warming in the eastern Pacific during the spring, as the cold tongue reaches its minimum westward extension, which supports high enough total SSTs to sustain tropical convection (Gadgil et al. 1984; Zhang 1993).

An important question is to what extent does the leading mode of coupled variability explain the total variability. The percent of explained variance (relative to the original data) of the leading two CCA modes is shown in Fig. 3, with the top edge of the bar describing the percentage associated with CCA-1 and the bottom edge indicating the percentage linked to CCA-2. The CCA modes, by design, optimize correlation between SST and OLR anomalies, but there is the possibility that they may fail to explain a substantial fraction of the total variance. Figure 3 shows that the leading CCA mode explains approximately $20 \%-45 \%$ of the total variance (depending on season and variable) and that this fraction of explained variance is greater than that of the second mode by a large margin except during the spring.

The leading CCA- 1 mode of SST reaches a peak in explained variance during the fall $(\sim 43 \%)$ while the peak in OLR occurs during the midwinter $(\sim 33 \%)$.
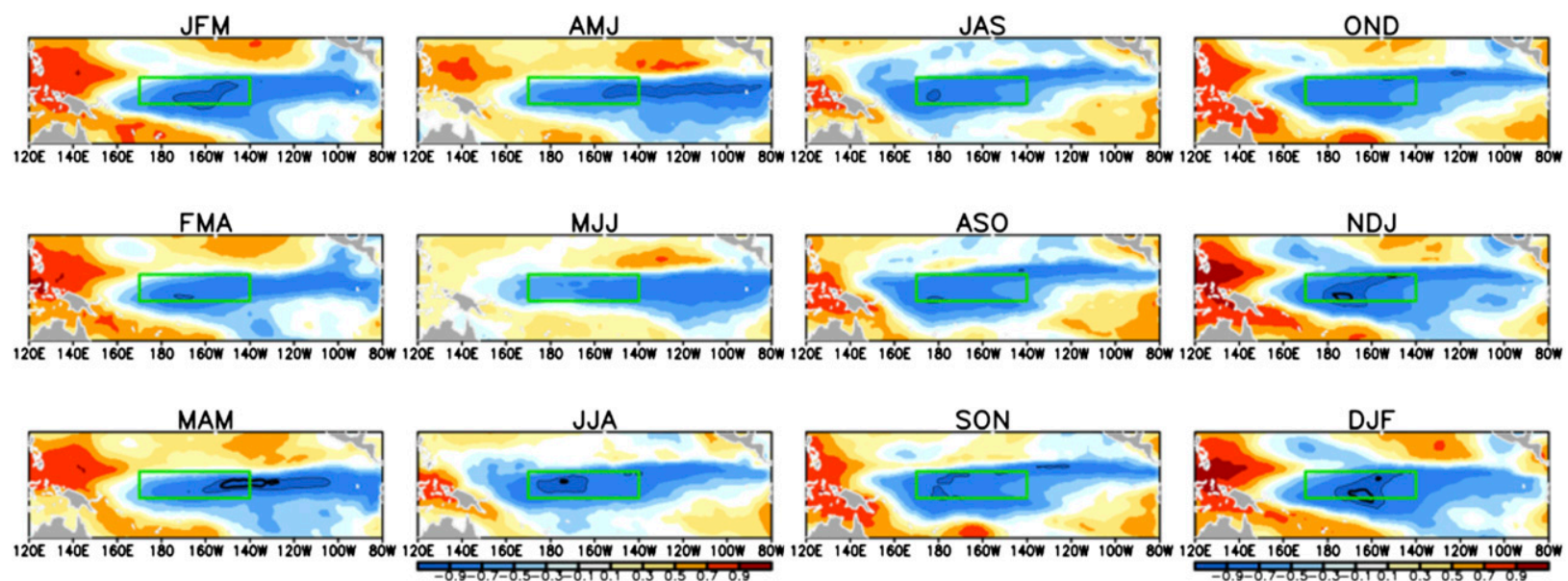

FIG. 2. As in Fig. 1, but for outgoing longwave radiation anomalies. The green box indicates the CP-OLR region $\left(5^{\circ} \mathrm{S}-5^{\circ} \mathrm{N}, 170^{\circ} \mathrm{E}-140^{\circ} \mathrm{W}\right)$. 

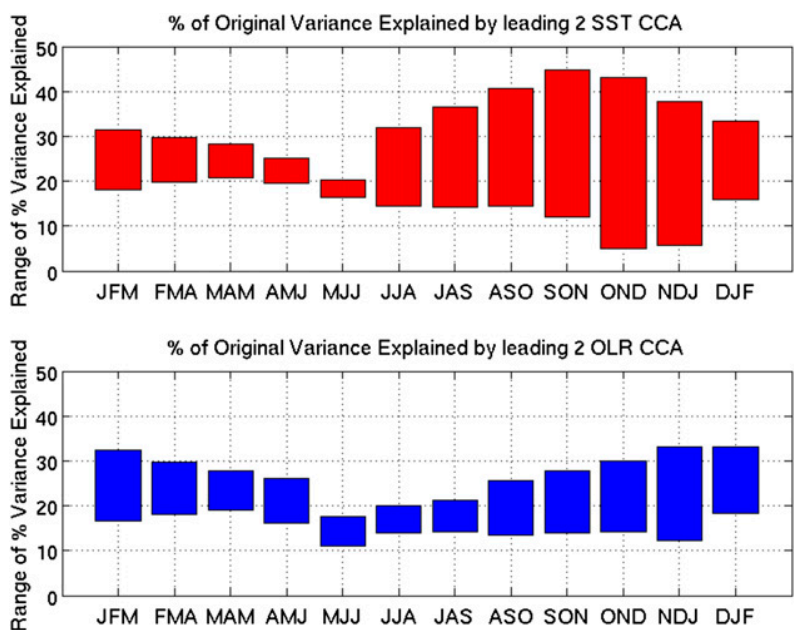

FIG. 3. The percentage of explained variance described by the leading two CCA modes relative to the (top) original SST or (bottom) OLR seasonally averaged data. The upper (lower) edge of the bar represents the explained variance described by the leading CCA-1 (second leading CCA-2) mode of SST or OLR.

From late summer [June-August (JJA)] to early winter [December-February (DJF)] the separation between the variance explained by the first two CCA modes is at least $15 \%$. The canonical correlations provide a measure of the coupling between SST and OLR for each CCA mode, and are shown in Fig. 4a. The canonical correlations of the first CCA mode exceed 0.95 throughout the year and those of the second mode exceed 0.85 .

A key question is the extent to which the regions of strongest coupling vary as a function of season, which helps to diagnose whether a seasonally invariant ENSO index is appropriate. Although the SST and OLR components display some longitudinal variation in the location of maximum correlations, overall they remain mostly consistent through the calendar year. The OLR pattern exhibits somewhat more seasonal variation than SST, especially below the equator east of $120^{\circ} \mathrm{W}$ where the correlation values are mostly not significant and switch from slightly negative in spring to slightly negative in fall.

Since the spatial structure of the leading CCA mode shows little variability through the year, there is the potential to define seasonally invariant indices that capture most of the variability of the CCA modes. In the case of SST, natural candidates are the standard Niño region indices. Figures $4 \mathrm{~b}$ and $4 \mathrm{c}$ assess the linear relation of Niño-3 and Niño-3.4 with the CCA time series and in doing so assess how well a seasonally invariant index performs. The Niño-3 index is more highly correlated across all seasons with the leading CCA mode than is the Niño-3.4 index (cf. black lines in Figs. 4b,c). The higher correlation of the Niño-3 index is particularly

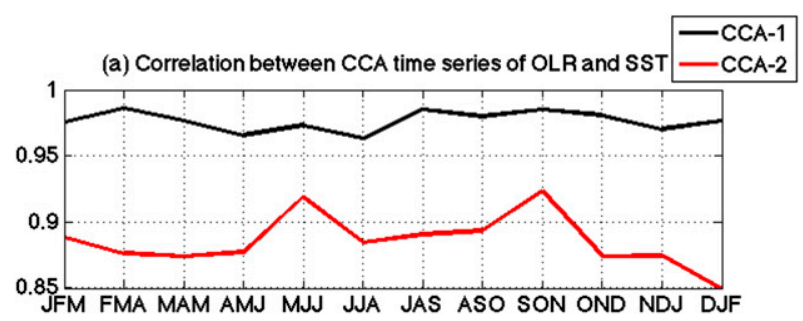

(b) Correlation of CCA SST time series with Nino-3

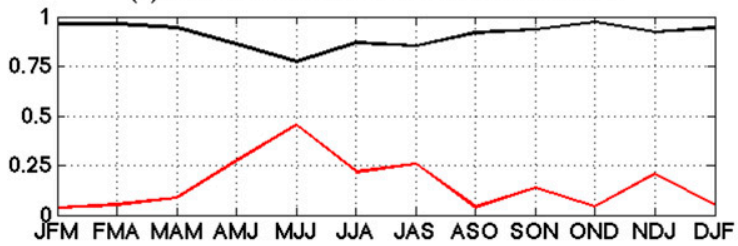

(c) Correlation of CCA SST time series with Nino-3.4

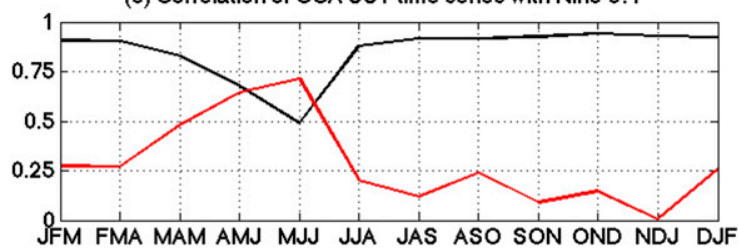

FIG. 4. For all overlapping seasons, the (a) correlation between the OLR and SST time expansion coefficients associated with the leading CCA-1 (black line) and second leading CCA-2 (red line). (b) The correlation between Niño-3 SST and CCA-1 (black) and CCA-2 (red) SST time series. (c) As in (b), but for Niño-3.4 SST.

evident during AMJ and MJJ when the Niño-3.4 correlation coefficients drop below 0.75 (black line in Fig. 4c). Niño-3.4 shows a substantial correlation (red line in Fig. 4c) during the spring with the second leading CCA-2 SST index, which by construction is uncorrelated with the leading CCA mode. Thus, during the spring, the Niño-3.4 region captures a roughly equal linear combination of CCA-1 and CCA-2 SST modes, while Niño-3 more faithfully represents the leading CCA-1 SST mode. However, the Niño-3 and Niño-3.4 correlations with the leading CCA-1 SST are not significantly distinct from each other during the fall and winter seasons.

The correlation maps can help explain the differing correlations of Niño-3 and Niño-3.4 with the leading CCA mode. While Niño-3.4 SST $\left(5^{\circ} \mathrm{S}-5^{\circ} \mathrm{N}, 170^{\circ}-120^{\circ} \mathrm{W}\right)$ mostly covers a high correlation region (purple box in Fig. 1), it is the Niño-3 SST region (green box in Fig. 1) that is slightly superior in representing coupled SSTOLR variability year-round. Niño-3 SST accomplishes this by extending farther to the east during the spring (from MAM through MJJ), capturing a larger area of highest correlations. During the spring the Niño-3.4 region excludes the strong coupling occurring closer to South America that Niño-3 includes.

The second leading CCA-2 pattern (not shown) is reminiscent of ENSO Modoki, with an opposite-signed 
(a) Correlation of CCA OLR time series with CP-OLR

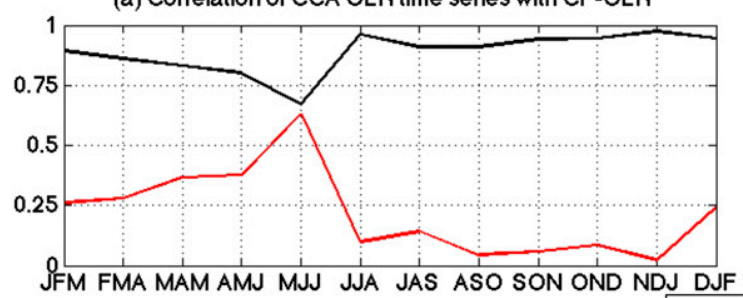

(b) Correlation of CCA OLR time series with EP-OLR $\begin{aligned} & \text { CCA-1 } \\ & -C C A-2\end{aligned}$

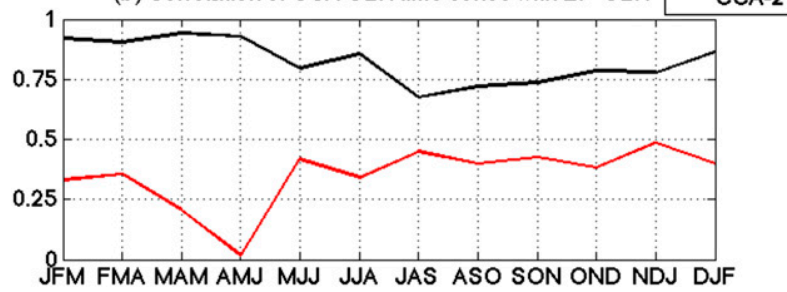

FIG. 5. For all overlapping seasons, the (a) correlation between CP-OLR and CCA-1 (black line) and CCA-2 (red line) time series. (b) As in (a), but for the EP-OLR time series.

SST or OLR dipole between the western and eastern Pacific. It has been argued that Modoki is an important and physical mode of tropical Pacific variability in its own right (e.g., Ashok et al. 2007). From Fig. 3, it is clear that CCA-2 explains a nonnegligible amount of variance $(\sim 5 \%-20 \%$ of the original data), but its percentage of explained variance has a larger separation from that of the leading CCA-1 during most seasons. It is only during the spring or summer, when CCA-1 explains less variance, that CCA-2 begins to rival CCA-1 in importance. Spring and summer also represent the time of year when ENSO is often in transition, which has led some to question whether a mode that resembles CCA-2 is physically meaningful or is an artifact of the analysis procedure (e.g., Lian and Chen 2012; L'Heureux et al. 2013).

Similar to the SST CCA correlation maps, the region of the OLR correlation maps associated with the largest correlations is also largely unchanged across all seasons, except during the period from MAM to MJJ when the maximum correlations extend farther eastward into the eastern Pacific Ocean (Fig. 2). On the basis of the CCA analysis, we define the central Pacific OLR region (CPOLR) as the area of $5^{\circ} \mathrm{S}-5^{\circ} \mathrm{N}, 170^{\circ} \mathrm{E}-140^{\circ} \mathrm{W}$ to the west of Niño-3 (green box in Fig. 2). This is our candidate for a seasonally invariant OLR index. The cold tongue of SSTs across the eastern Pacific, over much of the year, is likely responsible for the lack of collocated OLR and SST correlations and the westward displacement of OLR closer to the Pacific warm pool.

During all seasons except MJJ, the CP-OLR index is well correlated $(r>0.8)$ with the leading CCA-1 OLR index (Fig. 5a). Only during MJJ does the CP-OLR index become also moderately correlated with the CCA-2
OLR index $(r \sim 0.6)$; this is the same season when Niño-3 and Niño-3.4 show higher correlations with CCA-2 SST index (Figs. 4b,c). The comparable correlation of CCA-1 and CCA-2 indices with multiple regional SST or OLR indices is suggestive of a lack of clear separation between the modes (North et al. 1982) during the late spring or summer.

To compare with the previously defined Chiodi and Harrison (2013) OLR index over the eastern Pacific $\left(160^{\circ}-110^{\circ} \mathrm{W}\right.$; hereinafter EP-OLR), Fig. 5 also shows the correlation of the EP-OLR index with the CCA-1 and CCA-2 OLR indices. During most of the year, EP-OLR is well correlated with the CCA-1 OLR index (black line in Fig. 5b). Compared to CP-OLR (black line in Fig. 5a), the EP-OLR index is slightly better correlated with the leading CCA-1 OLR index during the spring (MAM through MJJ). During the late summer through winter (JAS through DJF), EP-OLR appears to be less correlated with CCA-1 OLR relative to CP-OLR.

\section{b. Degree of linearity between Niño-3 SST and regional OLR}

While CCA may identify strongly correlated structures in the data, it does not demonstrate how linear the relationship is between SST and OLR. Advantages of finding a linear relationship between indices are that all phases of ENSO are simultaneously classified and are less dependent on sampling. To uncover the fit between SST and OLR, Fig. 6 shows scatterplots of the Niño-3 SST index and three OLR indices. The OLR indices are CPOLR, EP-OLR, and a third Indo-Pacific index $\left(120^{\circ}-\right.$ $\left.160^{\circ} \mathrm{E}\right)$. During ENSO, OLR anomalies over the IndoPacific are typically anticorrelated with anomalies over the central and eastern Pacific (Fig. 2). The scatterplots reveal the different relation of the EP-OLR and CP-OLR indices with Niño-3 despite the correlations being about the same. Because the relation does not look strictly linear in all cases, a nonparametric fit or local linear regression is used to approximate a nonlinear best fit between the two variables. Color shading indicates the distance between the individual month and the best-fit line.

Overall, the CP-OLR region is mostly linearly related to Niño-3 SST with positive Niño-3 values (El Niño) linked to negative CP-OLR, and vice versa (Fig. 6). In contrast, Indo-Pacific OLR anomalies are often positive when Niño-3 is positive. However, negative Niño-3 values appear to be split between positive and negative OLR values indicating that La Niña events do not necessarily favor enhanced convection in the region. Tighter clustering about the best-fit line is indicative of a stronger relationship between Niño-3 and CP-OLR relative to OLR over Indonesia. Though the EP-OLR region overlaps with CP-OLR, the relationship between Niño-3 

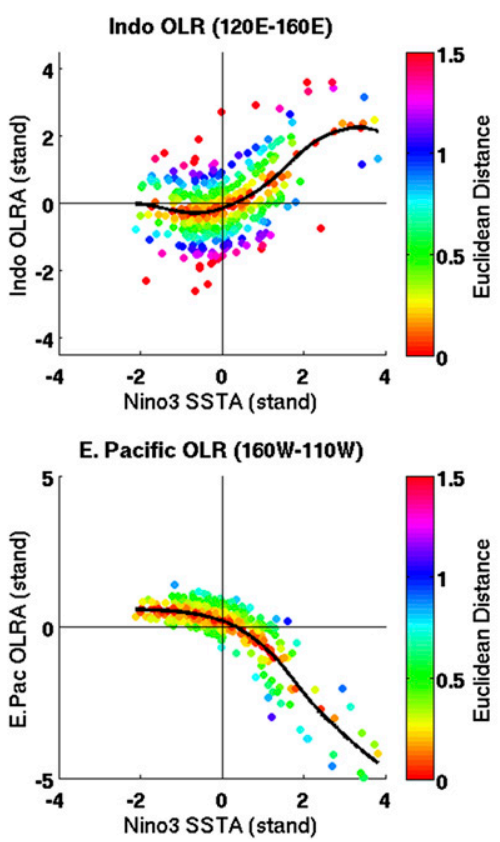

and EP-OLR is considerably more nonlinear. For negative Niño-3 values, the best-fit line describes a clear association with weakly positive EP-OLR values. For positive Niño-3 values, EP-OLR demonstrates considerable variance, spanning from near zero to strongly negative EP-OLR values. The strong nonlinearity arises in part when total SSTs in Niño-3 are near their peak, which increases the potential of a stronger negative OLR response in the eastern Pacific (e.g., Zhang 1993). Out of the three regions, it is evident that the Niño-3 SST and CP-OLR relationship has the dual attributes of being mostly linear and strongly related.

\section{c. North American impacts from a combined OLR and Niño-3 SST index}

In section 3a, we showed that both Niño-3 SST and CP-OLR are strongly correlated with the leading mode of coupled Pacific variability over nearly all seasons. Now, we ask whether these ENSO-related indices have a robust impact on North American climate. To answer this question, we correlate the indices with contemporaneous seasonal temperature and precipitation. Even if temperature and precipitation were unrelated to the indices, we would expect correlations at roughly $5 \%$ of the North American grid points to exceed the 95\% significance level purely by chance. Spatial correlation of the temperature and precipitation fields increases the fraction of grid points expected to display spurious correlations. The Monte Carlo field significance procedure described in section 2 is used to identify seasons during which the fraction of grid points with significant correlations exceeds that expected by chance.

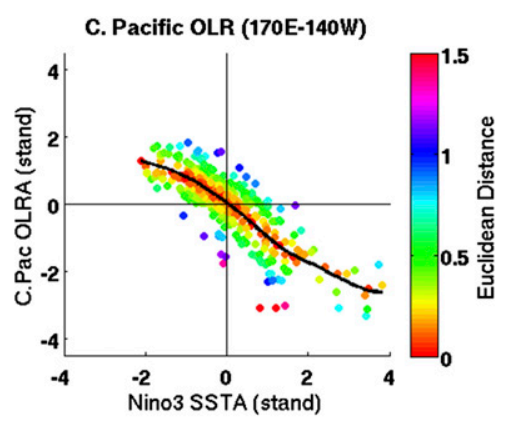

FIG. 6. Scatterplot between standardized, monthly Niño-3 SST index and standardized, monthly OLR over (top left) Indonesia $\left(5^{\circ} \mathrm{S}-5^{\circ} \mathrm{N}, 120^{\circ}-160^{\circ} \mathrm{E}\right)$, (top right) the central Pacific $\left(5^{\circ} \mathrm{S}-5^{\circ} \mathrm{N}, 170^{\circ}-140^{\circ} \mathrm{W}\right)$, and (bottom left) eastern Pacific $\left(5^{\circ} \mathrm{S}-5^{\circ} \mathrm{N}, 160^{\circ}-110^{\circ} \mathrm{W}\right)$ for the period 1982-2013. The local linear regression is shown in black. Shading represents the Euclidean distance between the local linear regression and each point.

Figure 7 shows that for precipitation the required fraction is $8 \%-10 \%$, while for temperature it is $14 \%-$ $17 \%$, depending on season. The greater threshold for temperature reflects the larger spatial scale of temperature variations. The top row of Fig. 7 compares the percentage of North American grid boxes that exceed the $5 \%$ level of local significance based on a randomly generated white noise time series (black line), the Niño3 SST index alone (red line), the CP-OLR index alone (blue line), and an equally weighted combined CP-OLR and Niño-3 SST index (green line). The equally weighted combined CP-OLR and Niño-3 SST index is the sum of the standardized Niño-3 index and the negative of the standardized CP-OLR index (or "inverted" index). One of the more striking features shown in Fig. 7 is that the CP-OLR index, on its own (blue line), describes slightly more overall temperature and precipitation variability than the Niño-3 SST index alone (red line). While each index is only field significant during the Northern Hemisphere winter and spring, it suggests that the CPOLR index is an equally, if not slightly more, capable descriptor of North American climate variability relative to the Niño-3 or Niño-3.4 SST indices (see Fig. S1 in the supplemental material).

This result then leads to the question of whether the combination of two indices would provide a better description of North American climate impacts than either the OLR or SST index alone. In the middle and bottom rows of Fig. 7 an "unequally weighted" combination (the weights vary in space and by season) of CP-OLR and Niño-3 is shown (green line). The $F$ test is used to evaluate whether the addition of the second index leads 

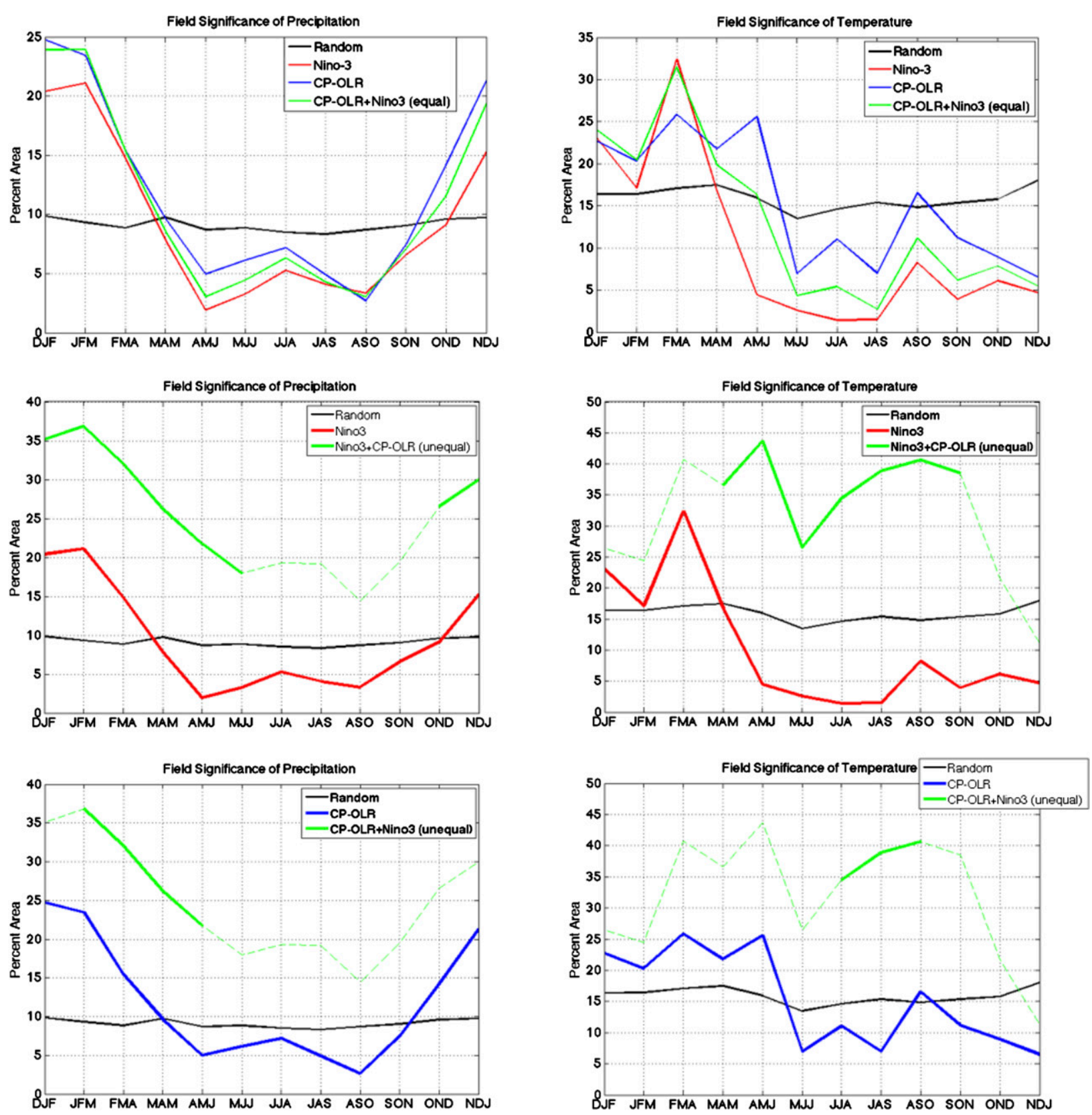

FIG. 7. Percent area across North America for (left) precipitation and (right) temperature for each 3-month overlapping season for 1982-2013. The black line represents the percentage of boxes based on the 95th percentile of results from 1000 random time series. The green line in the top row shows the equal weight of CP-OLR and Niño-3. The green lines in the middle and bottom rows show the unequal weighting of Niño-3 or CP-OLR. Thicker green lines show when the addition of Niño-3 or CP-OLR is field significant.

to a significant reduction in sum-squared error over the model with just one index (see section 2). As will be shown, the order in which the predictors are added can lead to differences in significance. Applying the same significance thresholds (black line), the solid, thick portion of the line shows when the inclusion of a second index is field significant, while the thin, dashed portion shows when it is not.
Our analysis suggests that, yes, the unequally weighted combination of the two most coupled tropical Pacific OLR-SST regions provides a better description for certain regions and seasons. In particular, we show that the addition of Niño-3 SST to the CP-OLR index alone is better suited to describing precipitation variability during JFM through AMJ than the CP-OLR index alone (Fig. 7; bottom-left panel). The converse is also true, meaning 
that addition of CP-OLR to the Niño-3 SST index alone provides an improvement in those same seasons (Fig. 7; middle-left panel). For temperature, the combination index provides significant explanatory power during JJA through ASO, no matter whether the Niño-3 SST or CPOLR index is added second (Fig. 7; middle- and bottomright panels).

Notably, there are several more field significant seasons when CP-OLR is added as a second predictor to Niño-3 SST (cf. thick green lines in Fig. 7; middle and bottom rows). Therefore, a combined SST-OLR index offers more improvement over using the Niño-3 SST index by itself, than when it is stacked up against just the CP-OLR index. This further substantiates the finding that, on its own, the CP-OLR index is a relatively more capable descriptor of overall seasonal North American climate variability than Niño-3 SST index alone.

So, which regions in North America are better explained by the addition of the CP-OLR or Niño-3 SST index to the single index? Figures 8 and 9 show the influence of these unequal weighted indices on precipitation and temperature, respectively. Here, we focus on those seasons that are field significant irrespective of the ordering of the predictors: JFM-AMJ precipitation and JJA-ASO temperature. The shaded regions depict locally significant explained variance $\left(r^{2} \times 100\right)$ based on the correlation using CP-OLR only (left column) or Niño-3 SST only (right column) with warm and cool colors expressing the sign of the correlation coefficient between the index and the field. Superimposed on the color shading are contours that show the additional explained variance using the combined index, or inclusion of Niño-3 SST as a second predictor to CPOLR (left column) and vice versa (right column). Thicker (thinner) contours indicate positive (negative) correlation coefficients between the second predictor and the field. Here the OLR index has been multiplied by -1 (inverted) so that positive OLR anomalies represent greater convection, allowing its anomaly sign to be consistent with, rather than opposite from, that of SST.

It is clear from Fig. 8 that, during the winter and spring, the combination SST-OLR index provides more expansive coverage of precipitation variability over the western and eastern United States than the CP-OLR index alone (left column) or over Mexico, New Mexico, and Texas relative to the Niño-3 SST index alone (right column). Thus, if the CP-OLR index were used by itself, it would not capture as much precipitation variability over the eastern and western United States as a combined index would. Likewise, if the Niño-3 SST index were used in isolation, it would miss potential precipitation impacts over Mexico, New Mexico, and Texas that a combined index captures. In general, El Niño (La Niña) contributes to an increase (decrease) in precipitation over the southern tier of the United States as documented in numerous studies (e.g., Ropelewski and Halpert 1986; Schonher and Nicholson 1989).

From Fig. 9, it is apparent that during the summer, the combined index describes more temperature variability over portions of central Canada, Newfoundland, and the western United States than the CP-OLR index alone (left column) and compared to the Niño-3 SST alone (right column). Again, the CP-OLR index on its own is linked to more widespread temperature variability than Niño-3 alone (cf. shading between left and right columns). Unlike precipitation though, many of the same regions are better described by the addition of a second index (contoured area), regardless of whether it is Niño-3 SST (left column) or CP-OLR (right column). During JJA and JAS, a combined index explains more variance over the western United States, with El Niño (La Niña) related to below-average (above average) temperatures. During JAS and ASO, temperature over central Canada and Newfoundland is better captured by a combined index as well; also generally related to below-average (above average) temperatures during El Niño (La Niña). However, over central Canada during JAS, the sign of the correlation coefficient depends on whether the CP-OLR or Niño-3 SST index is used.

Given that the EP-OLR index is slightly better correlated with the leading CCA-1 OLR index during certain seasons, we also examine field significance using EP-OLR instead of CP-OLR in Fig. 10. Comparing it with Fig. 7, it is apparent that CP-OLR alone overall describes more seasonal North American climate variability than EP-OLR alone (blue line in Fig. 10). In addition, during most seasons, the Niño-3 SST index alone appears to exceed the number of correlated areas associated with EP-OLR alone. Together, the combined index of EP-OLR and Niño-3 SST does not significantly explain additional temperature or precipitation variability relative to either index alone. The lone exception is during the summer seasons when it appears that the addition of EP-OLR to Niño-3 SST describes more precipitation variability (Fig. 10, middle-left panel). However, the converse situation reveals no such benefit using a combined index (Fig. 10, bottom-left panel) and either index alone is insignificant during the summer seasons. Therefore, using the CP-OLR index is more effective to describe linear impacts. On the other hand, Chiodi and Harrison (2013) show that the EP-OLR is able to identify strong El Niño events when eastern Pacific SSTs warm up enough to trigger convection. It is during these strong El Niños when impacts over the United States become more significant (e.g., Larkin and Harrison 2005; Goddard and Dilley 2005). 
Addition of Niño-3 (contour) to CP-OLR only (shading)
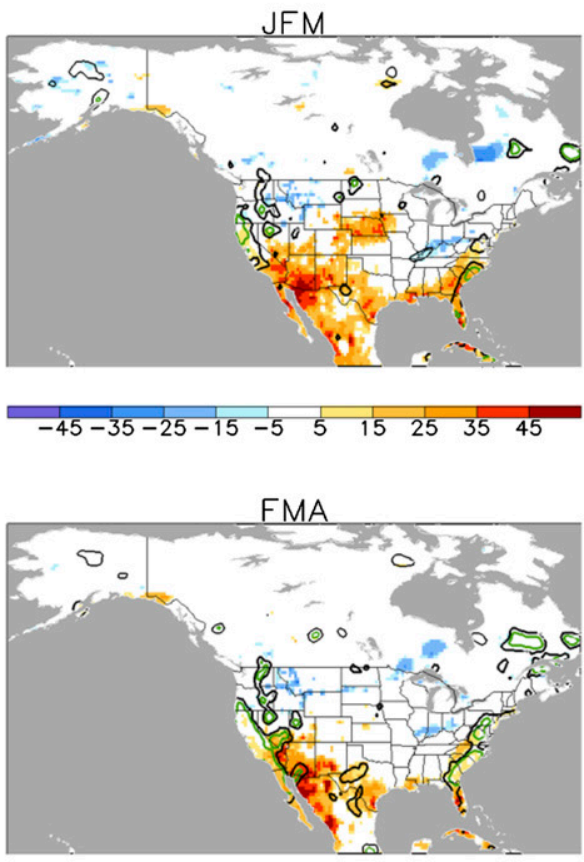

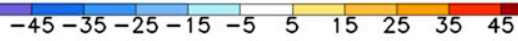

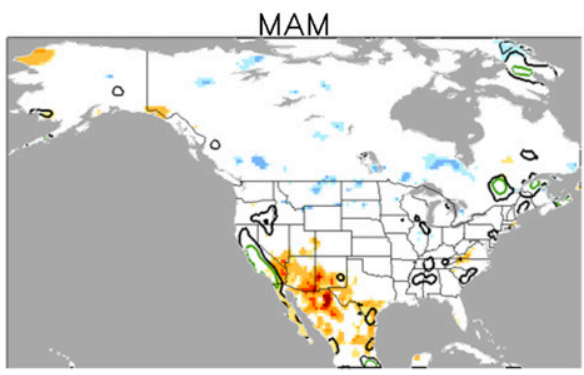

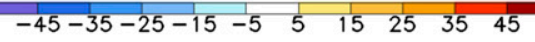

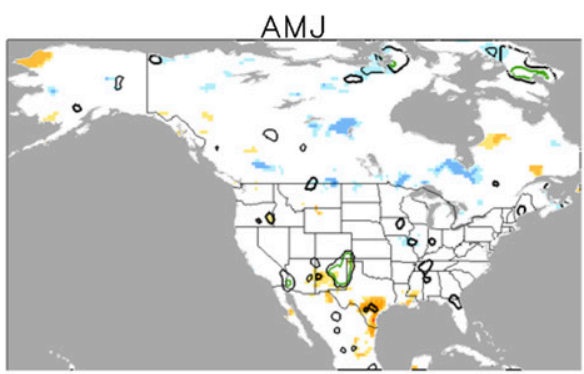

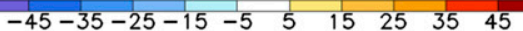

Addition of CP-OLR (contour) to Niño-3 only (shading)
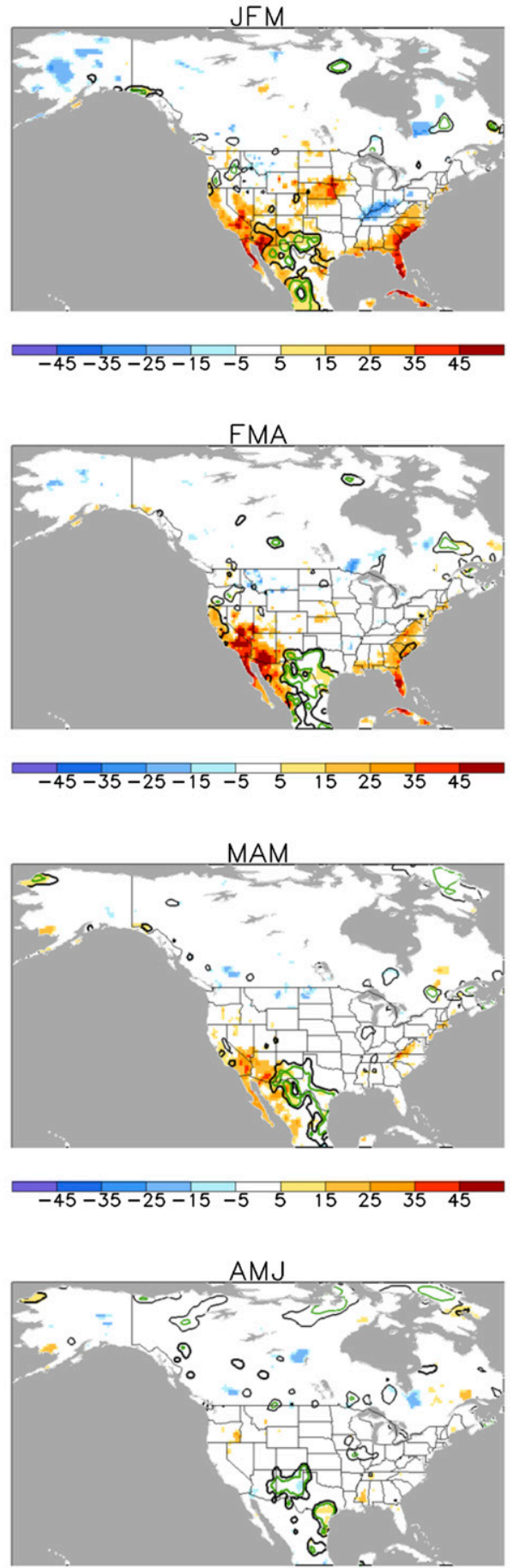

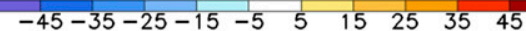

FIG. 8. Correlation coefficients squared $(\times 100)$ show the percentage of explained variance between the linear regression model predicted and observed precipitation over North America for JFM-AMJ. Shaded regions show the one-predictor model based on (left) the CP-OLR-only index or (right) the Niño-3-only index. Black/green contours show where the unequal weighted two-predictor model (Niño-3 SST or CP-OLR) explains additional variance beyond the one-predictor model. Black (green) contours show 10\% (20\%) additional explained variance. Thicker (thin) contours indicate positive (negative) correlations between the anomalies and second predictor. Reddish (bluish) color shading also indicates where the Niño-3 SST (at right) or CP-OLR (at left) correlation coefficient is positive (negative). Only areas that are statistically significant are displayed. 
Addition of Niño-3 (contour) to CP-OLR only (shading)
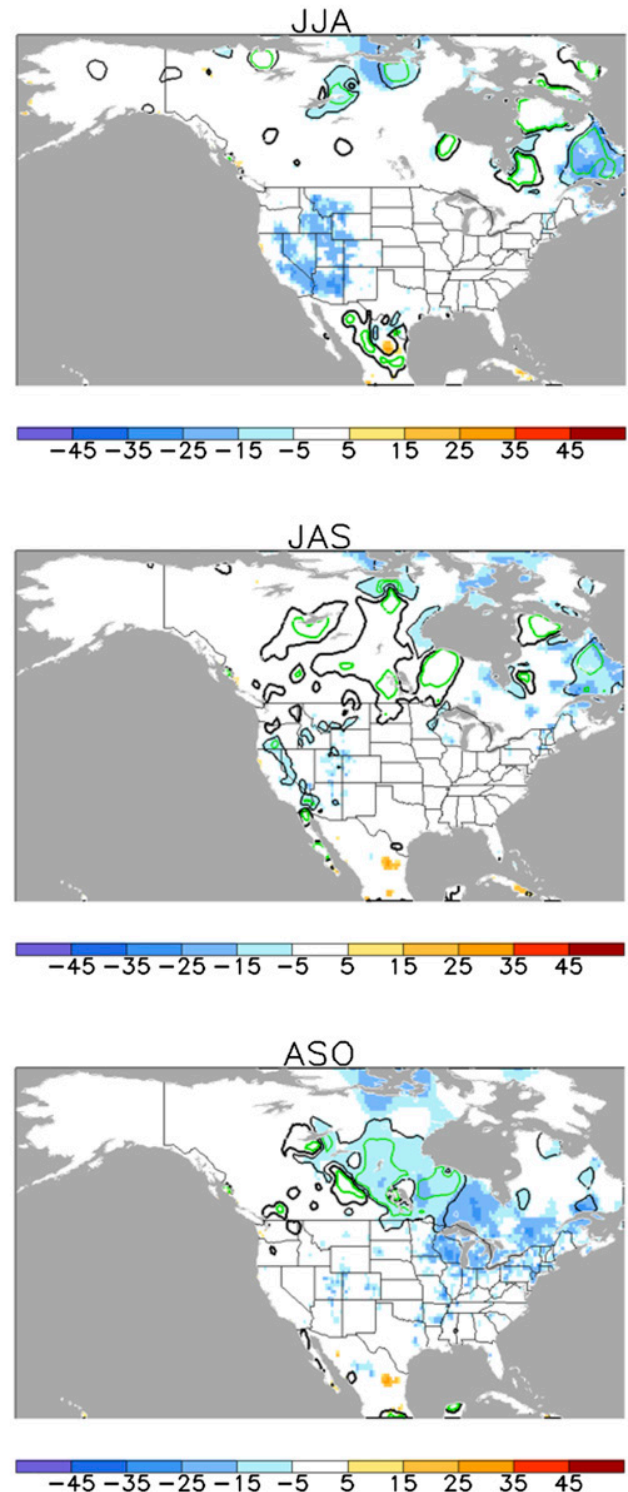

Addition of CP-OLR (contour) to Niño-3 only (shading)
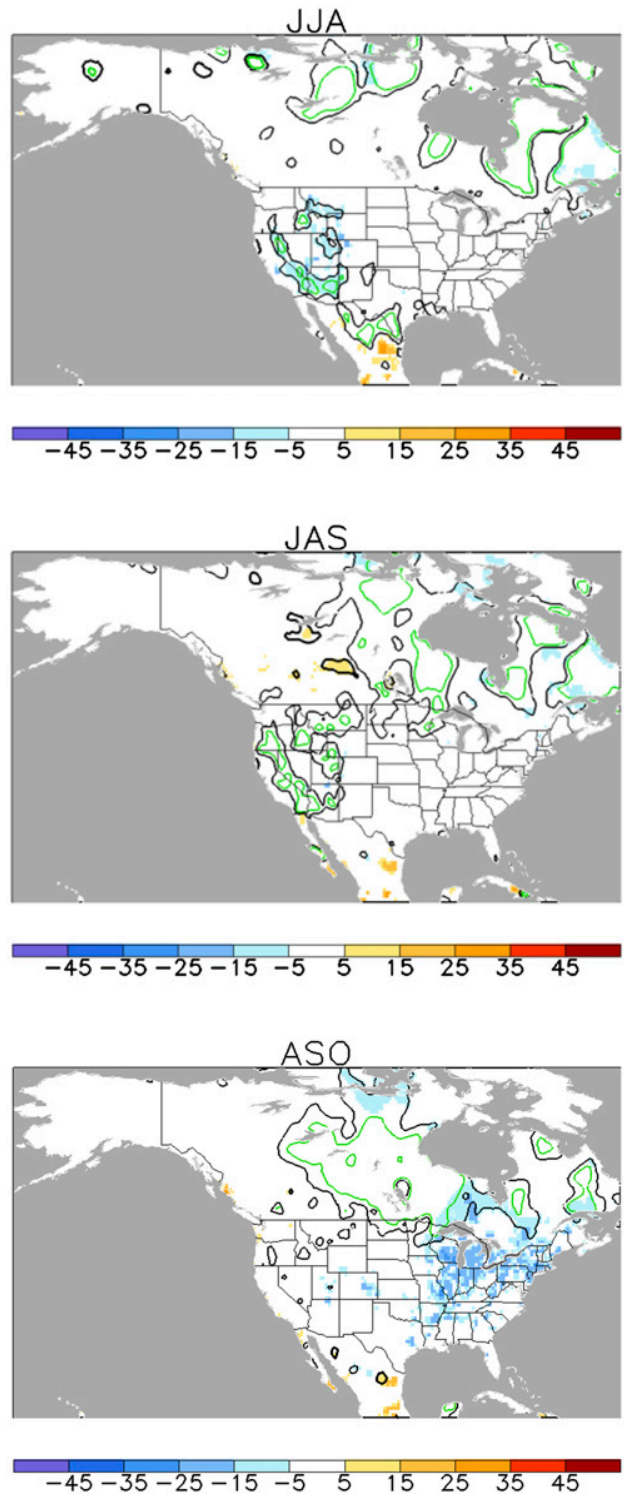

FIG. 9. As in Fig. 8, but for temperature over North America for JJA-ASO.

\section{Summary and discussion}

Our approach defines ENSO as the leading coupled pattern of tropical Pacific variability using OLR and SST. After creating combined indices based on the significantly coupled, seasonally invariant regions of OLR and SST, we correlate these indices with North American climate. Historically, the Niño-3.4 SST index has been used as the primary index to assess the status and prediction of ENSO. Our goal was to assess whether important ENSO impacts over North America are missed when an SST or OLR index is used in isolation and whether a combined index is required to represent these impacts. Our main results are briefly summarized as follows:

1) After coupled tropical Pacific SST-OLR regions are established using the leading CCA, it is the Niño-3 SST region that emerges as better coupled with OLR overall. However, the benefit of using this region arises only during the spring seasons (AMJ and MJJ) when coupling shifts farther east, as the other seasons are equally well correlated with Niño3.4 SST.

2) The central Pacific (CP) OLR region is well correlated with the leading CCA mode. The 

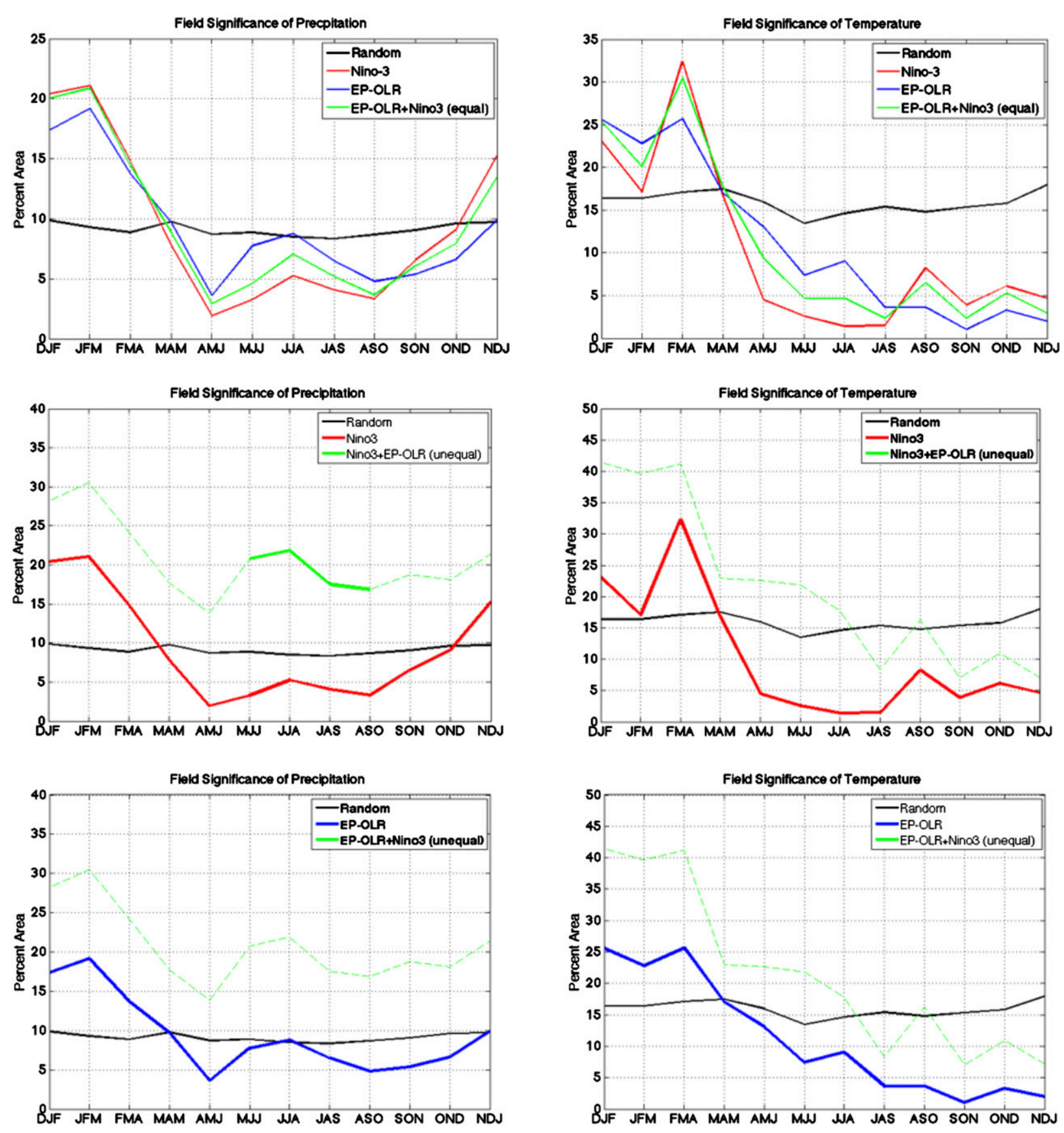

FIG. 10. As in Fig. 7, but for EP-OLR.

relationship between the CCA index and the eastern Pacific (EP) OLR region is weaker during most seasons, and the EP region is not as linearly related to SSTs as the CP OLR region, especially during La Niña.

3) The unequally weighted combined index of Niño-3 SST and CP-OLR explains more North American precipitation variability from JFM through AMJ and more temperature variability during JJA and ASO.
On its own, CP-OLR appears to slightly edge the Niño-3 SST index in describing North American climate.

Given these results, should the operational Niño-3.4 SST index be abandoned and replaced with the Niño-3 SST or CP-OLR indices? From the perspective of obtaining the most significantly coupled regions in the tropical Pacific, Niño-3.4 SST easily rivals Niño-3 SST in 
nearly all seasons except for the spring. From the standpoint of using an ENSO index that best describes North American climate, the impacts associated with Niño-3.4 SST, or its combination with CP-OLR, do not describe significantly more variance in North American climate than its Niño-3 counterpart, with the exception of precipitation variability during JJA and JAS (cf. Fig. S1 and Fig. 7). On the whole, the currently operational Niño-3.4 SST index is related well enough to tropical Pacific OLR and North American impacts to be an effective index in monitoring and prediction. However, the results here suggest that CP-OLR should be added to the suite of operational ENSO indices, along with a possible combined index. While not investigated in this paper, the implication is that CP-OLR provides a more direct link between heating in the tropical Pacific and the teleconnections that eventually impact North America. More work is clearly needed to better understand the seasonal-to-interannual predictability and prediction of OLR, which has historically been focused primarily on SSTs.

One downside to the unequal weights combined index presented here is that the weights vary spatially making the practical application of such a combined index challenging. In operations, a single combined index of SST and OLR would be a more ideal way to ascertain North American climate. As part of future work, precipitation and temperature could be reduced to principal components (PCs) that explain some fixed percentage of total variability. Then a CCA of the PCs and the tropical Pacific indices of OLR and SST could be calculated in order to obtain a set of weights. The stability of these weights and degree to which the combined index reproduces the scale of the impacts identified in this study would need to be evaluated.

The primary advantages of providing the linear perspective offered within this paper are that such linear relationships are versatile, easily adopted to many applications, and withstands greater sampling uncertainty. For example, in the nonlinear example shown in Fig. 6, the best fit between EP-OLR and Niño-3 SST can change with the removal of less than a dozen months with positive Niño-3 index values. Add the significant internal noise of the middle-to-high latitudes (e.g., Deser et al. 2012) to this uncertainty, and then one can envision how subsetting the historical record into much smaller sample sizes can lead to significant sampling error. Within a 30-yr record, there are often less than $10 \mathrm{El}$ Niño or La Niña events and changes in the interannual variability of ENSO from decade to decade can be considerable (Wittenberg 2009; Newman et al. 2011; Hu et al. 2013). However, the classification of a separate EPOLR index, as Chiodi and Harrison (2010, 2013) demonstrate, can capture significant nonlinear impacts that arise from strong El Niños.

While limited sampling does not preclude investigation of nonlinear impacts on the United States, it does argue for additional methodologies to bolster confidence, such as extending the length of the historical OLR record or supplementing observational-based analysis with model simulations, which can provide many more realizations. However, the fidelity of the models to capture the physical linkages between tropical Pacific OLR and SSTs and North American climate might be hampered by common cold tongue and double ITCZ biases (Mechoso et al. 1995; Lin 2007). To reduce these errors, large ensembles (e.g., Deser et al. 2014) along with flux corrections (Dai 2006; Magnusson et al. 2013) may increase the reliability and confidence in the model representation of tropical Pacific convection and more robustly confirm nonlinear teleconnections with North America.

Acknowledgments. We are grateful for comments on the manuscript by two anonymous reviewers, as well as, Kristopher Karnauskas, Emily Riddle, Emily Becker, and also discussions with Tim DelSole, Bob Livezey, Matt Newman, and Andy Chiodi who helped to scope this project and provided valuable suggestions.

\section{REFERENCES}

Ashok, K., S. K. Behera, S. A. Rao, H. Weng, and T. Yamagata, 2007: El Niño Modoki and its possible teleconnection. J. Geophys. Res., 112, C11007, doi:10.1029/2006JC003798.

Back, L. E., and C. S. Bretherton, 2009a: On the relationship between SST gradients, boundary layer winds, and convergence over the tropical oceans. J. Climate, 22, 4182-4196, doi:10.1175/2009JCLI2392.1.

$\longrightarrow$, and $-2009 \mathrm{~b}$ : A simple model of climatological rainfall and vertical motion patterns over the tropical oceans. J. Climate, 22, 6477-6497, doi:10.1175/2009JCLI2393.1.

Barnett, T. P., and R. Preisendorfer, 1987: Origins and levels of monthly and seasonal forecast skill for United States surface air temperatures determined by canonical correlation analysis. Mon. Wea. Rev., 115, 1825-1850, doi:10.1175/ 1520-0493(1987)115<1825:OALOMA > 2.0.CO;2.

Barnston, A. G., M. Chelliah, and S. B. Goldenberg, 1997: Documentation of a highly ENSO-related SST region in the equatorial Pacific. Atmos.-Ocean, 35, 367-383, doi:10.1080/ 07055900.1997.9649597.

— M. K. Tippett, M. L. L'Heureux, S. Li, and D. G. DeWitt, 2012: Skill of real-time seasonal ENSO model predictions during 2002-11: Is our capability increasing? Bull. Amer. Meteor. Soc., 93, 631-651, doi:10.1175/BAMS-D-11-00111.1.

Charney, J. G., 1963: A note on large-scale motions in the tropics. J. Atmos. Sci., 20, 607-609, doi:10.1175/1520-0469(1963)020<0607: ANOLSM $>2.0 . \mathrm{CO} ; 2$.

Chen, M., W. Shi, P. Xie, V. B. S. Silva, V. E. Kousky, R. Wayne Higgins, and J. E. Janowiak, 2008: Assessing objective techniques for gauge-based analyses of global daily precipitation. J. Geophys. Res., 113, D04110, doi:10.1029/2007JD009132. 
Chiodi, A. M., and D. E. Harrison, 2010: Characterizing warmENSO variability in the equatorial Pacific: An OLR perspective. J. Climate, 23, 2428-2439, doi:10.1175/2009JCLI3030.1.

_ , and — 2013: El Niño impacts on seasonal U.S. atmospheric circulation, temperature, and precipitation anomalies: The OLR-event perspective. J. Climate, 26, 822-837, doi:10.1175/ JCLI-D-12-00097.1.

Dai, A. G., 2006: Precipitation characteristics in eighteen coupled climate models. J. Climate, 19, 4605-4630, doi:10.1175/ JCLI3884.1.

DelSole, T., and X. Yang, 2011: Field significance of regression patterns. J. Climate, 24, 5094-5107, doi:10.1175/ 2011JCLI4105.1.

Deser, C., A. S. Phillips, V. Bourdette, and H. Teng, 2012: Uncertainty in climate change projections: The role of internal variability. Climate Dyn., 38, 527-546, doi:10.1007/ s00382-010-0977-x.

M. A. Alexander, and B. V. Smoliak, 2014: Projecting North American climate over the next 50 years: Uncertainty due to internal variability. J. Climate, 27, 2271-2296, doi:10.1175/JCLI-D-13-00451.1.

Fan, Y., and H. Van den Dool, 2008: A global monthly land surface air temperature analysis for 1948-present. J. Geophys. Res., 113, D01103, doi:10.1029/2007JD008470.

Furtado, J., E. DiLorenzo, B. Anderson, and N. Schneider, 2012: Linkages between the North Pacific Oscillation and central tropical Pacific SSTs at low frequencies. Climate Dyn., 39, 2833-2846, doi:10.1007/s00382-011-1245-4.

Gadgil, S., P. V. Joseph, and M. V. Joshi, 1984: Ocean-atmosphere coupling over monsoon regions. Nature, 312,141-143, doi:10.1038/ 312141a0.

Goddard, L., and M. Dilley, 2005: El Niño: Catastrophe or opportunity? J. Climate, 18, 651-665, doi:10.1175/JCLI-3277.1.

Gruber, A., S. Xiujuan, M. Kanamitsu, and J. Schemm, 2000: The comparison of two merged rain gauge-satellite precipitation datasets. Bull. Amer. Meteor. Soc., 81, 2631-2644, doi:10.1175/ 1520-0477(2000)081<2631:TCOTMR > 2.3.CO;2.

Hu, Z.-Z., A. Kumar, H.-L. Ren, H. Wang, M. L'Heureux, and F.-F. Jin, 2013: Weakened interannual variability in the tropical Pacific Ocean since 2000. J. Climate, 26, 2601-2613, doi:10.1175/JCLI-D-12-00265.1.

Johnson, N. C., 2013: How many ENSO flavors can we distinguish? J. Climate, 26, 4816-4827, doi:10.1175/JCLI-D-12-00649.1.

Kao, H.-Y., and J.-Y. Yu, 2009: Contrasting eastern Pacific and central Pacific types of ENSO. J. Climate, 22, 615-632, doi:10.1175/2008JCLI2309.1.

Karnauskas, K. B., 2013: Can we distinguish canonical El Niño from Modoki? Geophys. Res. Lett., 40, 5246-5251, doi:10.1002/ grl.51007.

Kousky, V. E., and R. W. Higgins, 2007: An alert classification system for monitoring and assessing the ENSO cycle. Wea. Forecasting, 22, 353-371, doi:10.1175/WAF987.1.

Larkin, N. K., and D. E. Harrison, 2005: Global seasonal temperature and precipitation anomalies during El Niño autumn and winter. Geophys. Res. Lett., 32, L16705, doi:10.1029/ 2005 GL022860.

L'Heureux, M. L., D. C. Collins, and Z.-Z. Hu, 2013: Linear trends in sea surface temperature of the tropical Pacific Ocean and implications for the El Niño-Southern Oscillation. Climate Dyn., 40, 1223-1236, doi:10.1007/s00382-012-1331-2.

Lian, T., and D. Chen, 2012: An evaluation of rotated EOF analysis and its application to tropical Pacific SST variability. J. Climate, 25, 5361-5373, doi:10.1175/JCLI-D-11-00663.1.
Liebmann, B., and C. A. Smith, 1996: Description of a complete (interpolated) outgoing longwave radiation dataset. Bull. Amer. Meteor. Soc., 77, 1275-1277.

Lin, J.-L., 2007: The double-ITCZ problem in IPCC AR4 coupled GCMs: Ocean-atmosphere feedback analysis. J. Climate, 20, 4497-4525, doi:10.1175/JCLI4272.1.

Lindzen, R. S., and S. Nigam, 1987: On the role of sea surface temperature gradients in forcing low-level winds and convergence in the tropics. J. Atmos. Sci., 44, 2418-2436, doi:10.1175/ 1520-0469(1987)044<2418:OTROSS >2.0.CO;2.

Livezey, R. E., and W. Y. Chen, 1983: Statistical field significance and its determination by Monte Carlo techniques. Mon. Wea. Rev., 111, 46-59, doi:10.1175/1520-0493(1983)111<0046: SFSAID $>2.0 . \mathrm{CO} ; 2$

Lopez, H., and B. P. Kirtman, 2013: Westerly wind bursts and the diversity of ENSO in CCSM3 and CCSM4. Geophys. Res. Lett., 40, 4722-4727, doi:10.1002/grl.50913.

Magnusson, L., M. Alonso-Balmaseda, and F. Molteni, 2013: On the dependence of ENSO simulation on the coupled model mean state. Climate Dyn., 41, 1509-1525, doi:10.1007/ s00382-012-1574-y.

Mechoso, C. R., and Coauthors, 1995: The seasonal cycle over the tropical Pacific in coupled ocean-atmosphere general circulation models. Mon. Wea. Rev., 123, 2825-2838, doi:10.1175/ 1520-0493(1995)123<2825:TSCOTT>2.0.CO;2.

Newman, M., S.-I. Shin, and M. A. Alexander, 2011: Natural variation in ENSO flavors. Geophys. Res. Lett., 38, L14705, doi:10.1029/2011GL047658.

North, G. R., T. L. Bell, R. F. Cahalan, and F. J. Moeng, 1982: Sampling errors in the estimation of empirical orthogonal functions. Mon. Wea. Rev., 110, 699-706, doi:10.1175/ 1520-0493(1982)110<0699:SEITEO > 2.0.CO;2.

Reynolds, R. W., N. A. Rayner, T. M. Smith, D. C. Stokes, and W. Wang, 2002: An improved in situ and satellite SST analysis for climate. J. Climate, 15, 1609-1625, doi:10.1175/ 1520-0442(2002)015<1609:AIISAS > 2.0.CO;2.

— T. M. Smith, C. Liu, D. B. Chelton, K. S. Casey, and M. G. Schlax, 2007: Daily high-resolution-blended analyses for sea surface temperature. J. Climate, 20, 5473-5496, doi:10.1175/ 2007JCLI1824.1.

Ropelewski, C. F., and M. S. Halpert, 1986: North American precipitation and temperature patterns associated with the El Niño/Southern Oscillation (ENSO). Mon. Wea. Rev., 114, 2352-2362, doi:10.1175/1520-0493(1986)114<2352: NAPATP $>2.0 . \mathrm{CO} ; 2$.

Schonher, T., and S. E. Nicholson, 1989: The relationship between California rainfall and ENSO events. J. Climate, 2, 1258-1269, doi:10.1175/1520-0442(1989)002<1258:TRBCRA > 2.0.CO;2.

Smith, C. A., and P. Sardeshmukh, 2000: The effect of ENSO on the intraseasonal variance of surface temperature in winter. Int. J. Climatol., 20, 1543-1557, doi:10.1002/ 1097-0088(20001115)20:13<1543::AID-JOC579>3.0.CO;2-A.

Stechmann, S. N., and H. R. Ogrosky, 2014: The Walker circulation, diabatic heating, and outgoing longwave radiation. Geophys. Res. Lett., 41, 9097-9105, doi:10.1002/ 2014 GL062257.

Takahashi, K., A. Montecinos, K. Goubanova, and B. Dewitte, 2011: ENSO regimes: Reinterpreting the canonical and Modoki El Niño. Geophys. Res. Lett., 38, L10704, doi:10.1029/ 2011 GL047364.

Tippett, M. K., A. G. Barnston, and S. Li, 2012: Performance of recent multimodel ENSO forecasts. J. Appl. Meteor. Climatol., 51, 637-654, doi:10.1175/JAMC-D-11-093.1. 
Trenberth, K. E., 1997: The definition of El Niño. Bull. Amer. Meteor. Soc., 78, 2771-2777, doi:10.1175/ 1520-0477(1997)078<2771:TDOENO > 2.0.CO;2.

Van Loon, H., and R. A. Madden, 1981: The Southern Oscillation. Part I: Global associations with pressure and temperature in northern winter. Mon. Wea. Rev., 109,1150-1162, doi:10.1175/ 1520-0493(1981)109<1150:TSOPIG > 2.0.CO;2.

Walker, G. T., and E. W. Bliss, 1932: World weather V. Mem. Roy. Meteor. Soc., 4, 53-84.

Wittenberg, A. T., 2009: Are historical records sufficient to constrain ENSO simulations? Geophys. Res. Lett., 36, L12702, doi:10.1029/2009GL038710.

Wolter, K., and M. S. Timlin, 2011: El Niño/Southern Oscillation behaviour since 1871 as diagnosed in an extended multivariate
ENSO index (MEI.ext). Int. J. Climatol., 31, 1074-1087, doi:10.1002/joc.2336.

Yin, X., A. Gruber, and P. Arkin, 2004: Comparison of the GPCP and CMAP merged gauge-satellite monthly precipitation products for the period 1979-2001. J. Hydrometeor., 5, 12071222, doi:10.1175/JHM-392.1.

Yulaeva, E., and J. M. Wallace, 1994: The signature of ENSO in global temperature and precipitation fields derived from the microwave sounding unit. J. Climate, 7, 1719-1736, doi:10.1175/ 1520-0442(1994)007<1719:TSOEIG > 2.0.CO;2.

Zhang, C., 1993: Large-scale variability of atmospheric deep convection in relation to sea surface temperature in the tropics. $J$. Climate, 6, 1898-1913, doi:10.1175/1520-0442(1993)006<1898: LSVOAD $>2.0 . \mathrm{CO} ; 2$. 